\title{
Creating a Framework to Recognize Context-Originated Factors in IS in Organizations
}

\author{
Tuija Tiihonen, Mikko Korpela, and Anja Mursu \\ University of Kuopio, HIS R \& D Unit, Finland \\ tuija.tiihonen@uku.fi,mikko.korpela@uku.fi \\ University of Kuopio, Department of Computer Science, Finland \\ anja.mursu@uku.fi
}

\begin{abstract}
Information system (IS) is a complicated structure of social and technical systems. They are part of every organization in western and developing countries. Uncertainty has always been a part of software and information system development, and working globally increases the uncertainty. To know some basic factors of the IS context, the interconnectedness of human and technological informatics in everyday work could be a way to decrease this uncertainty. In this paper, we present the theoretical basis of three context models to construct a framework to be used as one method when evaluating different IS contexts in IS use and development.
\end{abstract}

Keywords: information system, context, information system development, information system use, organization

\section{Introduction}

In the age of globalization, the world is becoming more and more interconnected, and information and communication technology (ICT) is becoming more important for everyone [Heeks 2002, Moyi 2003, Walsham et al. 2006, WITFOR 2005]. All organizations utilize information systems (IS), which increasingly use ICT. Good application or design of an information system is not obvious when it is based on technical requirements only, without understanding how people work and what their environment and context is [Kling 1999]. Even if ICT and IS development include universal codes and rules, the transfer of information systems is not an automatic success. Uncertainty has always been a part of software and information system developing projects; the mismatch of cultures and contexts can cause problems

Please use the following format when citing this chapter:

Tiihonen, T., Korpela, M., Mursu, A., 2006, in IFIP International Federation for Information Processing, Volume 223, Social Informatics: An Information Society for All? In Remembrance of Rob Kling, eds. Berleur, J., Numinen, M. I., Impagliazzo, J., (Boston: Springer), pp. 367-379. 
especially when working globally [Lai et al. 2003, Molla et al. 2005]. Knowing the basic factors of the IS context could be a way to decrease this uncertainty. To find these factors the information systems should be approached not only as a technical but also as a social system, [Walsham et al. 1990], which is also the principle of Social Informatics (SI) research [Kling 1999].

This research is part of the INDEHELA -programme. INDEHELA [Korpela et al. 2006] (Informatics Development for Health in Africa) has, in its previous phases, produced knowledge about information systems development practices mainly in Nigeria [Mursu 2002, Soriyan 2004]. In IS development there is need for contextoriented implementation, yet there is not much analytical research conducted on the social context [Avgerou et al. 2004]. The existing IS context studies are not particularly focused on producing theories, frameworks, or methods to observe the working environment, but more on the technical and economical aspects of developing IS. The object of the present phase of the INDEHELA is to focus on this deficiency. The aim is to develop a framework as a method to evaluate different IS contexts in IS use and development. The partners of the INDEHELA in this phase are in Finland, Nigeria, Mozambique, and South Africa.

The main research question is: How to recognize contextual factors that affect IS development and use? How would we find these factors? What are these factors like? How can the factors be used in the evaluation of IS use and development? The objective of this research is to create a framework to help observe the context and to find answers to the former questions.

In this paper, we present the theoretical basis to create this framework. Section 2 presents the theoretical background and it includes three models of context: the scopes of context, the categories of contextual factors, and the analysis levels of contexts. Section 3 concerns the methodology we use. Section 4 is a first attempt to use the ideas of the context models as a framework to elicit different contextual factors.

\section{Theoretical background}

The concept of context is huge and very difficult to define or explain. In this section, we define these sub concepts of context: the scopes of contexts, the categories within contexts, and the levels of contexts.

\subsection{Scopes of Context}

Context surrounds and affects every item, idea, or action. The context may create or increase, as well as hinder, limit, or decrease those phenomena. Context is an essential concept in different fields of science. On the most concrete level, for example, the context applies in archaeology. Any artefact found by an archaeologist is tightly connected to the context it is found in. The context may help define the purpose of an object, or an object can lighten the surrounding context and culture.

Anthropology is a science that studies humankind. In anthropology, context is a little more abstract concept than in archaeology, but very essential as well. In the 
context definition of Tapaninen (2005), there are three levels of contexts: cultural context, historical context, and immediate context. Since this research considers the information system in organization mostly as a social system, a system that exists only when humans are acting in it, the idea of context used here is the anthropologist definition.

To the three anthropological levels of contexts, we have added nature, which is the largest concept. Nature is everything that exists without humans such as vegetation, fauna, the ground, and weather. Nature is the basis that has to exist before any kind of culture can appear, and where there is human made culture there is cultural context. Cultural context is all that human actions and ideas have created. Cultural context includes all habits, ideas, norms, values, or beliefs. Because of cultural context is the historical context, which is all of the historical events that have marked its cultural context. The innermost 'top' context is the immediate context, which includes all of the other contexts in it: the entire environment, its action and interaction, the actors and roles, in the situation where it exists. On this basic idea of different contexts, we have created the bowl model of scopes of context (Fig. 1).

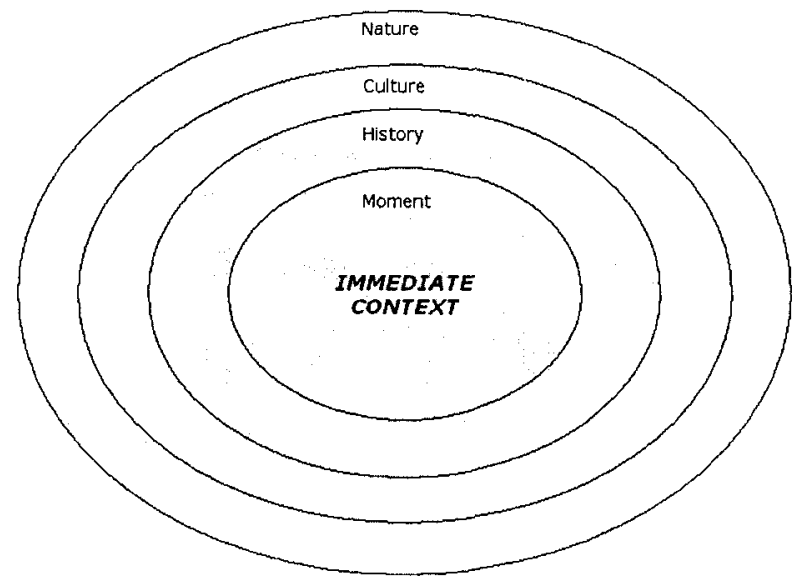

Figure 1. The bowl model of scopes of contexts

As illustrated in Figure 1, the context is like a bowl of water: nothing can be separated to belong to only one part of the context. We can take, for example, skills of an individual in an organization: the cultural context may define what kind of education is respected. The historical context may affect how this kind of education in this culture is possible to arrange. In addition, the history of every individual, her/his experiences of life, in the surrounding nature and culture, history and the moment are relevant. Accordingly, the education and experience, which lead to the skills of an individual, is a wholeness of culture, history, and the moment. The lines between these different contexts are lines drawn on the water. Different layers of contexts are present in the everyday working environment of any information system. 


\subsection{Categories of Contextual Factors}

Within context, many environmental factors affect the information system. In this research, we have separated five main categories: socio-political environment, infrastructure, organizational culture, economy, and human resources. (See Figure 2.) The selection of these categories is based on the findings in literature [Ciborra 2004, Lai et al. 2003, Molla et al. 2005, Mosse 2005, Soriyan 2004], and on our own work and research experiences in information systems. In this phase, the categories are quite tentative; the categorization will elaborate along the research process.

The socio-political environment includes political and military safety and stability, as well as hierarchical constructions and social security of the citizens of the country [McGrew 2002]. In addition, beliefs, values, norms, and habits are parts of socio-political environment. Socio-political environment sets the potentiality to all the other categories.

The definition of infrastructure we use in this research is all manmade possibilities, which include roads, buildings, power supplies, communication systems, water systems, et cetera. We may call this kind of infrastructure a 'technical infrastructure', although in some definitions the technical infrastructure includes only the machinery used inside an organization. There are wider definitions to infrastructure as well, which include education and banking [Okunoye 2006] or qualifiers like human resource infrastructure and economic infrastructure [Williamson et al. 2004].

Organizational culture is a specific manmade ecosystem that can only appear inside the surrounding culture, but within an organization's own rules and habits. Organizational culture defines the ways of communication, hierarchy, and all of the habits of work inside the organization. It includes the shared values, beliefs, norms, and expectations within the system [Okunoye 2003]. Organizational culture is the personality of the organization [McNamara 2005]. It is a daughter of culture, or cultural context; it varies between countries, but also between organizations within a country.

In information systems, as well as in many other manmade systems, almost everything depends on economy. It is not only the question of 'how much money do we have', but also 'how do we use this money we have', concerning the economic skills and decisions [McGrew 2002, Wilson et al. 2002].

The last category is something that needs all other categories, but it is also needed to realize all others: human recourses. Again, we have the fact that an information system is a human system; thus, it cannot exist without human resources [Ciborra 2004, Wilson et al. 2002]. Human resources include all the knowledge and skills that are to be used in the organization, and how these resources are used. The human resources are tied tightly with economy, socio-political environment, and organizational culture. 


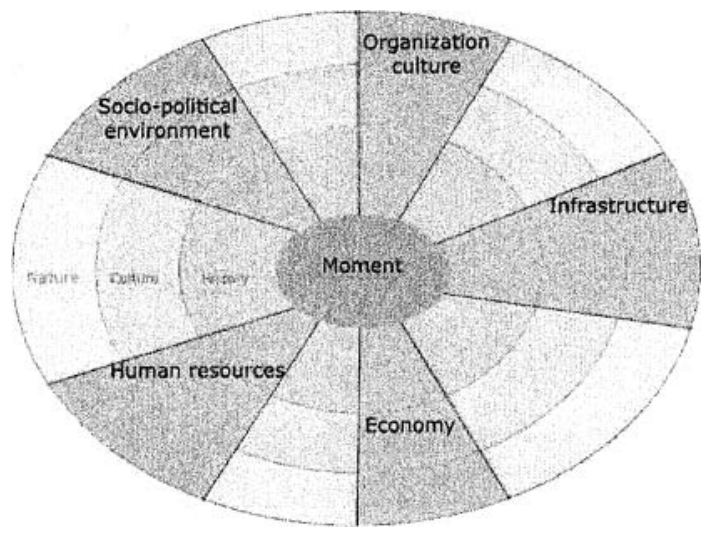

Figure 2. Categories of contextual factors

All five categories relate to each other and they are present in every information system. These categories appear as sector slices in the bowl model as presented in Figure 2. The empty space between the slices implies other parts of society that are not significant in light of this research.

\subsection{Levels of context}

When examining information systems there are many different social and technical levels with relation to the viewpoint the system is studied. Yet not all the levels exist in every context. For example, the working cultures of Africa can be radically different from those in Western countries [Walsham 2000]. However, in the IS study it is significant to have models to approach the use of information systems and IS development, regardless of the culture we are working on [Walsham et al. 2006].

Two times four levels of analysis model was created by Korpela et al. (2001) to define on which level of surrounding social ecosystem the information system is situated, despite the culture or context, on a globally comparable way. Figure 3 is modified from the original figure to be more illustrative.

The different rows of the model represent the level in the human society, and the columns are for units to be analyzed, and the relations between these units. The lowest level is individual and on this level, the unit is a person. These persons can form different kinds of groups like women, men, doctors, clerks, and so on. Second, group or activity level is for groups, operational units that together create 'product'. On the second level we can define groups like operating groups and first aid groups, which can interact with each other. The third level in this model is the organizational level. It signifies mainly organizations or units of organizations that work locally (e.g. district hospital), and the cooperation between organizations. The highest level in the original model was the societal level, which represents country. Yet globalization brings international connections between countries, and to this version, we have added the global level, which is the top level of information systems. On the societal and global levels stay the big and multinational organizations, e.g. at the 
societal level is the governmental health care system and at the global level international health programmes.

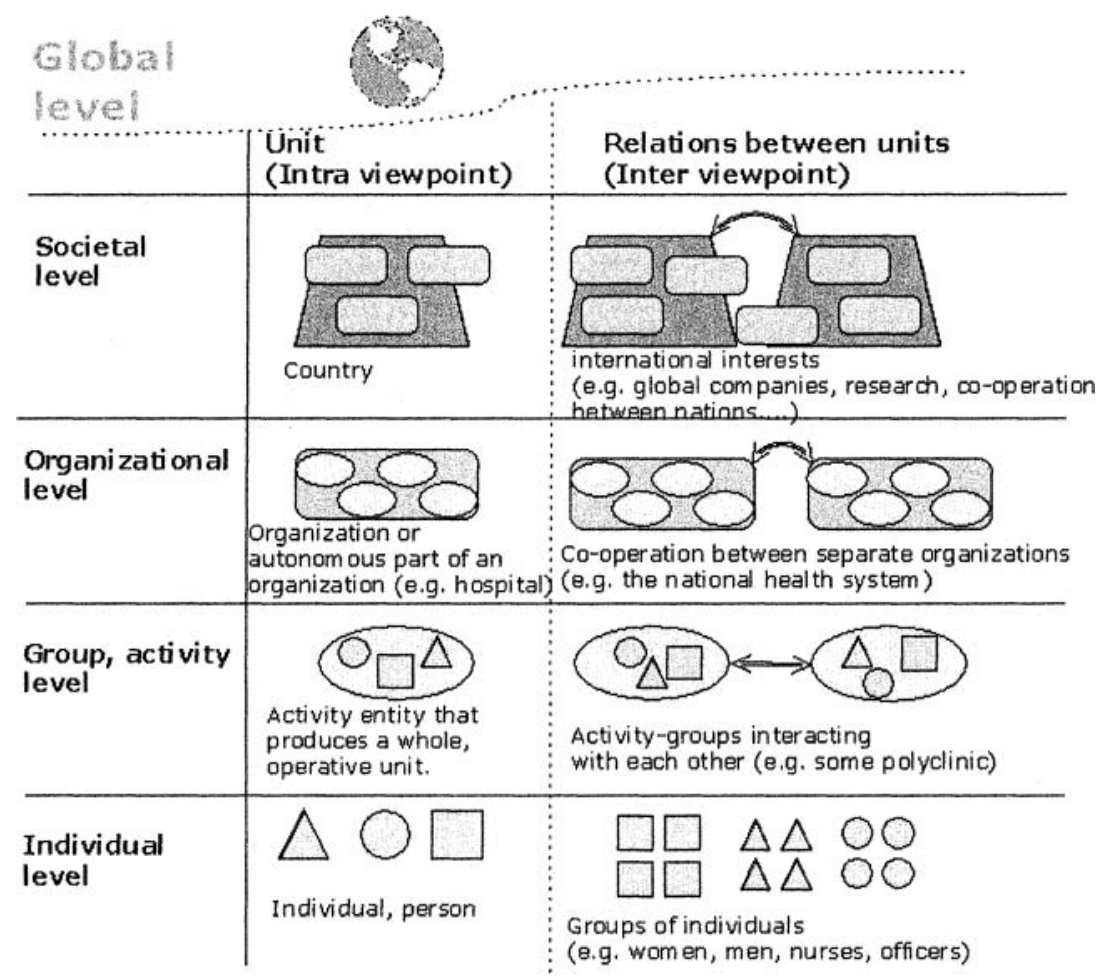

Figure 3. Levels of analysis. Modified from Korpela et al. ( 2001).

All of the higher levels are present and affect the lower levels. Depending on the analysis level, the bowl model has different status. In the societal and organizational levels, the impact of cultural and historical context is very strong. Therefore, we should view the factors of this level in the light of the culture and history of the surrounding human ecosystem. The immediate context then appears on the lower, group, and individual levels.

In this study, the focus is to study information system in organizations. On an organizational level, we look at organizational information systems affected by the culture, history, and the society as a whole, but the functionality of the organization realizes on the group level and individual level and is a construction of immediate contexts. 


\section{Methodology}

Our objective is to create a framework to recognize context-originated factors. We have started this based on the theoretical models presented in the previous chapter. In this section, we describe how we have applied the models, the research approach, and the research data.

\subsection{Research Approach}

This research began from literature, articles, reports, and other secondary data. This data has been the basis for the three models of context in the theoretical background. The assumptions for building the interview material are based on the secondary data. Yet all the existing literal material is in practice for some other reason than describing context, so it can only help to make some guidelines, not work as a research material itself. The research is iterative: the first frame to the research was created with secondary data, and first part of primary data was collected by using this frame. This primary data will be analysed by applying the first frame, and the analysis will produce a new iteration to create the final framework.

The research is qualitative and interpretive. Contextual factors in the use of information systems are very little researched outside of risk management. This research aims to find contextual factors, not classify them. We are not looking for good or bad factors, nor are we going to find any causes and effects. This is a research of context, but not a contextual analysis, for the objective is not to understand the immediate context but detect the context and to define it as neutrally as possible. In this research, the objective is to apply the frame under development in as many different information systems as possible.

\subsection{Primary Data and Fieldwork Methods}

The intention is to get material as widely as possible, so the deep case studies, action research, or any other deep interpretive methods are not part of this study. Furthermore, there is no resource to stay longer in Africa or travel there often, so the methods to collect primary data in this research are mainly by interview and conversation. We obtained primary data from Finland, South Africa, and Mozambique.

First, we had to decide what kind of factors we were looking for. To research information system context is quite a large area, and there are neither certain questions nor right answers. Again, the information system is a human system, and the reality for every individual is different. To build an interview we used the five categories (infrastructure, economy, socio-political environment, human resources, and organization culture) and created questions that would be situated in a certain category.

We structured the interview on certain question groups: 1) Basic Questions (name, age, and so on), 2) Work (working title, role in the organization, and so on), 3) Technology (availability of technology), 4) Motivation, 5) Environment and Infrastructure, 6) Hierarchy, and 7) Human Relations in Working Environment. The 
structure of the questions was quite strict, including a detailed question series for all of these groups. Some questions included word lists, which we illustrated during the interviews, and we asked some questions about these words. Most important was the list of items that might threat the functioning of the information system. These items were collected from different reports and articles, mostly about information system risk management.

The strict questions worked quite well in Finland. However, during the first interview in South Africa, we realised the difference between cultures: These people talk! One does not have to ask every detail separately, only themes. According to our experience, all of the people in the world like to talk about their work, but the way they do it depends on their culture. Therefore, after the first interview in Africa we combined the strict questions to wider, more thematic questions.

Soon we found that the questions were not important at all. Instead, the value of the word lists proved to be the most important part of the interview. Instead of questions, which always include some kind of supposition, the neutral list of words gave the people interviewed a wider area to tell what she/he really thought. The viewpoint, values, and the meaning of word came from her/his reality. We still have some questions, but the basics of the interviews are the wordlists. An interviewed person is able to talk freely and the interviewer(s) could make defining questions as needed. This method seems to work really well in this kind of research, where there are no straight answers, not even straight questions.

\subsection{Secondary Data}

Secondary data from INDEHELA and Health Information Systems Programme (HISP) partners will be used to complete the primary data. HISP is a health information system program at the University of Oslo. It started as a local pilot project in South Africa in 1994; nowadays it has broadened to several other developing countries in Africa and Asia [HISP 2006].

This research was conducted mostly in Finland; thus, the collection of the material is and will be done in Africa. Since the resources for us to stay doing field research are quite limited, and we have partners staying in Africa (and also other parts of the world) in INDEHELA and HISP programmes, the co-operation in research gives us quite a large amount of secondary data we use in this research. Cooperation is crucial, firstly to cover a wider area than one could do alone; secondly, a cross-cultural research team is quite essential when trying to create a framework that would work in different cultures. In addition, the local contacts are most important when arranging interviews to other countries.

\section{Testing the framework: Situation analysis of HMIS, South Africa}

At this moment, we have created a theoretical basis frame of the three context models. To improve this towards a working framework it requires testing with different kinds of research materials (e.g. case reports and interview material) of 
different information systems to find the weaknesses and the strengths of the frame. This section presents the first applying of the context models as a framework.

The material studied here is from HISP partners: the report of situation analysis of HMIS by Louisa Williamson and Vincent Shaw [Williamson et al. 2004]. It is a report of the status of the District Health Information System (DHIS) and hospital and Primary Health Care (PHC) services in the North West Province in South Africa. The report itself is an analysis of information systems with key objectives, components of functioning IS, mainly on the data flow inside the health organization. The material of this report was collected through a survey of selected facilities, and with interviews with key personnel. Since the purpose of this report is mainly to develop the dataflow, it will not include all of the information we need to use this framework in full. The test output is also biased, since data in this report emphasis is to find possible faults in the context; the existing positive factors are reported less than negative factors. The country (societal level) context is not described in this report; hence, this report applies to people familiar with it.

The reported units are on the organizational level: district or sub-district hospitals and one provincial office. Although the analysis report concentrates on the functioning of the information system, its dataflow through the group, or even individual level (primary health care can be a health station with only one nurse) to the top, societal level, so that the level of the contexts depends on the analyzed item. In this paper, we have taken the liberty to combine the different source units; although the data of the report was collected in separated units, it was studied as data from one organization.

The socio-political environment in South Africa has gone through a major change during the last ten years, which also includes the health care system. The importance of health management is approved, and nowadays it is beginning to be realized. Since the nature, culture, or historical scopes of context are not part of the report, we feel it worthwhile to add a little about the cultural and historical contexts of South Africa from our own point of view. We have seen when visiting South Africa how strongly the cultural and historical contexts are present and how society has and is going through major changes. Yet this does not affect the immediate context in information systems as much as could be presumed. Instead, the people are willing to build a new working society together; there cannot be seen fear of the new. In the report studied, we can see this through the enthusiasm to work in new systems and desire for training. However, some doubts about the usefulness of training are also mentioned.

The factors of organizational culture and closely related human resources are often noticed in this report. Major changes have occurred in the organizational structure, and senior management has been changed. The conventions inside the organization are not clear or are often quite vague. The lack of continuity in management has affected negatively upon the ensured stability of cohesive policy and capacity development. The organizations lack job descriptions, as well as data flow, communication, and feedback policy. Lack of determination of the information needed causes an overload of information. Furthermore, there is a wide range of data collection tools. 
The enthusiasm of the staff is mentioned. However, there is a lack of knowledge, skills, and experience, which complicates working. There is also a lack of 'buy in': the people cannot see the point of the data collection, the data can be too difficult, the tools are inappropriate, and the employees are too busy to do this 'extra' work. They feel that they do not get enough support from management. Heavy workload is also reported. The turnover is remarkable and rapid through the organization, both at the organizational management level and at the group level employees.

Economy or infrastructure is not the focus of this report; accordingly, many factors of these categories do not appear. The importance of financial resources is clearly present in many factors: lack of human resources as the ongoing need of training and deficient staff; lack of adequate computers and tools; and heavy workload. Infrastructure is mentioned in that the staff members have general access ICT equipment, but there are problems in connectivity, as well as a lack of willingness to use them. In addition, the lack of office space is mentioned, but with no further explication.

\section{Discussion}

The most positive aspect about testing the context models was to realize how some factors, which were already familiar before, were found again from a different view. This kind of finding supports one of the objectives of the framework: how to find the 'obvious things' in the information system of the working environment. The framework is not at its best when used on a single case, but still is useful to give different viewpoints. It helps to gather items (or factors) with similar categories or scopes, but it would be most useful when comparing different information systems.

As mentioned earlier, the report studied here is an analysis mainly on the data flow inside the health organization. If the three models of contexts would have been on the base when this report material was collected and analyzed it might had given a richer picture of the system environment. For example, separating the level of context would have located the data more clearly; also, some description of the historical and cultural context would have been illustrative, not only to the view of foreign researcher, but also for the local researchers to 'take a step back' in order to get a wider viewpoint. The specified data from economical and infrastructural categories in the report is also quite limited. Even if these items were not essential to the report, they still may have affected the contextual factors in the information system.

The categories of contexts will need some redefinition. Some factors did not exactly fit in any category of the bowl model, e.g. the data collection tools (registers, books, forms). Generally, we can see them as a part of the organizational culture, when the tools are defined by management or in practice approved. However, what if there is no real organizational culture yet? Could the choosing of the tools be a reflection of socio-political environment, or is it only an economical necessity? Testing the context framework surfaced many questions similar to these. There may be a need for some different categories, and the existing ones should be defined more exactly, if possible. 


\section{Conclusion}

The object of this study was to construct a theoretical basis to a framework for IS contexts study. Now we have three basic models (scopes of contexts, categories of contextual factors, and levels of contexts), which we can use as a frame to study different IS context material. We have collected primary data such as interviews in South Africa and Mozambique during November 2005. Further interviews will take place in Finland, as well as in rural areas regarding health information systems and in urban areas regarding non-health information systems. Cooperation with partners will also bring some secondary data to study. The research will get clearer points as to where to approach when this material is studied within the frame. The categories on the contexts will get some kind of priority, and the structure of the categories may change. The iteration is going on.

In the first test, the frame showed some positive aspects as well as some imperfections. In any case, it appears to be quite useful, at least worth further development. The frame of models of contexts is free to use for anyone interested, and as we need as many cases studied as possible, we would be very interested in the results that using this frame may produce.

\section{References:}

1. [Avgerou et al. 2004] Avgerou, C, and Madon, S, Framing IS Studies: Understanding the Social Context of IS Innovation. In: Avgerou, Ciborra, Lang (eds.) The Social Study of Information and Communication Technology, (Oxford University Press 2004) pp. 162-184

2. [Ciborra 2004] Ciborra, C, Encountering Information Systems as a Phenomenon. In: Avgerou, Ciborra, Lang (eds.) The Social Study of Information and Communication Technology, (Oxford University Press 2004) pp. 17-37

3. [Heeks 2002] Heeks, R, Failure, Success, and Improvisation of Information Systems Project in Developing Countries, Development Informatics, WP series, Paper No. 11, (Institute of Development Policy and Management, Manchester 2002) http://unpan 1.un.org/intradoc/groups/public/documents/NISPAcee/UNPAN015601.pdf (March 16, 2006)

4. [HISP 2006] The homepage of HISP (Health Information Systems Programme), University of Oslo, http://www.hisp.org (January 1, 2006)

5. [Kling 1999] Kling, R, What is Social Informatics and Why Does it Matter? D-Lib Magazine, Vol. 5 No. 1, January 1999

http://www.dlib.org/dlib/january99/kling/01kling.html (February 23, 2006)

6. [Korpela et al. 2001] Korpela, M, Mursu, A, and Soriyan, H. A, Two Times Four Integrative Levels of Analysis: A Framework. In: Russo NL, Fitzgerald B, DeGross JI, (eds.) Realigning Research and Practice in Information Systems Development. The Social and Organizational Perspective. IFIP TC8/WG8.2 Working Conference, Boise, Idaho, USA, July 27-29, (Boston: Kluwer Academic, 2001) p. 367-377.

7. [Korpela et al. 2006] Korpela, M, Mursu, A, Soriyan H. A, de la Harpe, R, and Macome, E, Information Systems Practice for Development in Africa: Results from INDEHELA. In: Howcroft, D, and De Gross J. I (eds.) Social Inclusion: Social \& 
Organizational Implications for Information Systems, Trauth, E, (Kluwer Academic, Boston, MA 2006) (forthcoming)

8. [Lai et al. 2003] Lai, S-Y, Heeks, R, and Nicholson, B, Uncertainty and Coordination in Global Software Projects: A UK/India - Centred Case Study, Development Informatics, WP series, Paper No. 17.

(Institute of Development Policy and Management, University of Manchester 2003) http:/www.sed.manchester.ac.uk/idpm/publications/wp/di/di_wp17.pdf (March 13, 2006)

9. [McGrew 2002] McGrew, A, Sustainable Globalization? The Global Politics of Development and Exclusion in the New World Order. In: Allen and Thomas (eds.) Poverty and Development into the 21st Century, (Oxford University Press 2002) pp. 345-364

10. [McNamara 2005] McNamara, C, Organizational Culture. Free Management Library, http://www.managementhelp.org_thry/culture/culture.htm (December 21, 2005)

11. [Molla et al. 2005] Molla, A, and Loukis, I, Success and Failure of ERP Technology Transfer: A Framework for Analysing Congruence of Host and System Cultures, Development Informatics, WP series, Paper No. 24,

(Institute of Development Policy and Management, Manchester 2005) http://www.sed.manchester.ac.uk/idpm/publications/wp/di/di_wp24.pdf (March 16, 2006)

12. [Mosse 2005] Mosse, E, Understanding the Introduction of Computer-based Health Information Systems in Developing Countries: Counter Networks, Communication Practices and Social Identity, A Case Study from Mozambique, Doctoral Thesis (University of Oslo 2005)

13. [Moyi 2003] Moyi, E. D, Networks, Information and Small Enterprises: New Technologies and the Ambiguity of Empowerment, Information Technology for Development, vol. 10 No 4 (IOS Press 2003) pp. 221-232

14. [Mursu 2002] Mursu, A, Information Systems Development in Developing Countries Risk Management and Sustainability Analysis in Nigerian Software Companies, Doctoral Thesis (University of Jyväskylä 2002)

15. [Okunoye 2003] Okunoye, A, Context-Aware Framework of Knowledge Management: Cultural and Infrastructural Considerations. In: Korpela $M$, Montealegre $R$, Poulymenakou A, (eds.) Organizational Information Systems in the Context of Globalization. IFIP TC8 \& TC9/WG8.2\& WG9.4 Working Conference on Information Systems Perspectives and Challenges in the Context of Globalization. In Progress Research Papers [CD-ROM], Athens, Greece, June 15-17, (IFIP 2003), pp 59-71

16. [Soriyan 2004] Soriyan, H. A, A Conceptual Framework for Information System Development Methodology for Educational and Industrial Sectors in Nigeria, Doctoral Thesis (Obafemi Awolowo University 2004)

17. [Tapaninen 2005] Tapaninen, A-M, Sosiaaliantropologian perusteet http://www.avoin.helsinki.fi/Kurssit/sosAntr/materiali/ (May 4, 2005), (Course material, in Finnish)

18. [Walsham 2000] Walsham, G, Globalization and IT: Agenda for Research. In Baskerville, R., Stage, J. and DeGross, J. (eds.) Organization and social perspectives on information technology: IFIP International Working Conference on the Social and Organizational Perspective on Research and Practice in Information Technology (TC8 
WG8.2), 9-11 June, Aalborg, Denmark. (Boston: Kluwer Academic Publishers 2000), pp.195-210

19. [Walsham et al. 1990] Walsham, G, Symons, V, and Waema, T (1990) Information System as Social Systems: Implications for Developing Countries. In: Bhatnagar and Bjorn-Andersen (eds.) Information Technology in Developing Countries, (Elsevier Science Publishers, Amsterdam 1990) pp 51-61

20. [Walsham et al. 2006] Walsham G, and Sahay, S, Research on Information Systems in Developing Countries: Current Landscape and Future Prospects, Information Technology for Development, Vol. 12 No 1 (Wiley Publishers 2006) pp 7-24

21. [Williamson et al. 2004] Williamson, L, and Shaw, V, Situation Analysis of HMIS in North West Province, Health Information Systems Programme South Africa, report 2004 (Unpublished)

22. [Wilson et al. 2002] Wilson, G, Heeks, R, Technology, Poverty, and Development. In: Allen and Thomas (eds.) Poverty and Development into the 21st Century, (Oxford University Press 2002) pp. 403-424

23. [WITFOR 2005] IFIP Wold Information Technology Forum, Gaborone Declaration 2005, http://www.witfor.org (December 2, 2005) 